\title{
SISTEM PENENTUAN KUALITAS PISANG MENGGUNAKAN METODE FUZZY TSUKAMOTO
}

\author{
Rofika Arista $^{1)}$, Miftahus Sholihin ${ }^{2)}$, Nur Nafi'iyah ${ }^{3)}$ \\ 1) Mahasiswa Program Studi Teknik Informatika Universitas Islam Lamongan \\ ${ }^{2,3)}$ Program Studi Teknik Informatika Universitas Islam Lamongan \\ email: rofikaarista@gmail.com ${ }^{1)}$,miftahus.sholihin@unisla.ac.id ${ }^{2)}$,mynaff26@gmail.com ${ }^{3)}$
}

\begin{abstract}
Abstrak
Pisang adalah buah yang memiliki rasa sangat manis dan aroma yang harum. Buah ini menjadi favorit banyak orang karena harganya yang terjangkau dan memiliki banyak manfaat dan nutrisi untuk tubuh. Penentuan kualitas pisang telah ditetapkan berdasarkan SNI 7422-2009 pisang. Tetapi kurangnya pengetahuan perusahaan ataupun konsumen dalam menentukan kualitas pisang mengakibatkan kesehatan menurun karena kesalahan mengkonsumsi buah pisang. Proses menentukan kualitas pisang berdasarkan 3 variabel kriteria, yaitu: ukuran, kecacatan dan kesegaran. Di mana hasil kualitas pisang terdapat kategori kelas C, B, A dan Super. Metode Tsukamoto dalam menentukan kualitas pisang menggunakan defuzzifikasi nilai rata-rata, dan menggunakan kriteria kualitas pisang yang terdiri dari tiga variable, yaitu ukuran, kecacatan, dan kesegaran. Hasil penelitian ini didapatkan kelas pisang berdasarkan kriteria yang diinputkan dan memiliki nilai akurasi sebesar $78 \%$.
\end{abstract}

Kata Kunci: SPK, Pisang, Fuzzy tsukamoto

\section{Pendahuluan}

Pada penelitian Shintiani dan kawannya membuat aplikasi untuk menentukan penyakit dan hama tanaman kakao menggunakan metode fuzzy tsukamoto. Aplikasi dibangun agar dapat membantu proses konsultasi penyakit dan hama tanaman kakao, dan memberikan solusi cara mengendalikannya[1].

Wortel merupakan tanaman yang banyak mengandung Vitamin A. Setiap individu gemar mengkonsumsi wortel untuk kesehatan mata dan cara hidup sehat. Dalam penelitian Widyansyah membuat aplikasi penentuan tinggi tanaman dengan metode fuzzy tsukamoto. Di mana inputan dari sistem ukuran dosis pupuk, serta tinggi tanaman. Hasil dari aplikasi presentasi ujicoba keberhasilan kesuburan tinggi tanaman wortel[9].

Untuk memperoleh pegawai yang berkualitas, perusahaan harus melakukan perekrutan pegawai dengan benar. Penelitian Nadia Roosmalita Sari, dan Wayan Firdaus Mahmudy bertujuan membuat aplikasi menentukan perekrutan pegawai baru dengan sistem inferensi fuzzy Tsukamoto. Aplikasi dapat memberikan informasi dan rekomendasi terkait calon pegawai pada perusahaan layak atau tidak diterima. Rekomendasi dan informasi yang disampaikan aplikasi sebagai bahan pertimbangan untuk menerima calon pegawai. Aplikasi ini memberikan hasil yang baik dengan hasil uji coba menggunakan analisis uji $\mathrm{T}[1]$.

Jamkesmas adalah suatu sistem untuk memberikan pelayanan kesehatan kepada warga msikin di Indonesia. Penelitian Miftahus Sholihindan kawannya membuat aplikasi penentuan apakah calon jamkesmas berhak menerima kartu atau tidak dengan menggunakan algoritma fuzzy tsukamoto. Aplikasi ini menggunakan 14 kriteria sesuai dengan aturan BPJS, dan hasil outputnya memberikan rekomendasi apakah warga tersebut layak atau tidak mendapatkan kartu jamkesmas dari BPJS[6].

Penelitian Kemal Farouq, dan Miftahus Sholihin membuat aplikasi menentukan kenaikan jabatan pegawai di BKD Lamongan. Aplikasi penentuan kenaikan jabatan pegawai negeri (PNS) kabupaten Lamongan menggunakan metode Fuzzy tsukamoto. Dan proses membangun aplikasi menggunakan bahasa pemrograman Java dan database Mysql[4].

Tujuan penelitian Tri Murti, dan kawannya untuk membantu PT Triprima Finance dalam memberikan pinjaman ke calon nasabah. Proses menentukan memberikan pinjaman kepada calon nasabah dengan menginputkan semua kriteria ke delama aplikasi. Selanjutnya sistem akan menentukan apakah calon nasabah diberikan pinjaman atau tidak[7].

Penelitian Evi Nur Azizah, dan Imam Cholissodin mengabungkan algoritma fuzzy tsukamoto dan algoritma genetika dalam menentukan harga perumahan. Proses menentukan harga perumahan dengan menentukan nilai keanggotaan dari fuzzy tsukamoto, selanjutnya mengcrossover serta memutasi sesuai tahapan algoritma genetika. Hasilnya difitnes agar menghasilkan nilai terbaik[3]. Proses menentukan kesehatan calon siswa SMK menggunakan algoritma fuzzy tsukamoto dengan empat variabel input, yaitu: umur siswa, jenis kelamin, tinggi badan serta berat badan. Output dari sistem adalah kelas kesehatan siswa. Aplikasi ini dapat membantu pihak sekolah proses menentukan calon peserta didik baru (Muqodimah Nur Lestari, Pio Arfianova Fitrizky[2].

Teknik dalam menentukan jumlah produksi barang dapat menggunakan algoritma fuzzy tsukamoto. Di mana inputan dalam algoritma adalah pemesanan, persediaan dan outputnya jumlah produksi. Hasil 
dari aplikasi yang dibangun mempunyai akurasi $96,91 \%[8]$.

\section{Metode Penelitian}

Gambaran sistem yang akan dibangun seperti Gambar 1 terdapat 3 proses utama yaitu fungsi keanggotaan, inferensi, dan defuzzikasi. Fungsi Keanggotaan, Fungsi keanggotaan bertujuan untuk mencari nilai tiap variabel yang diinputkan. Inferensi, Inferensi bertujuan untuk menginputkan nilai dari fungsi keanggotaan tiap variabel kedalam aturan yang telah ditentukan. Defuzzikasi, Defuzzikasi adalah suatu himpunan fuzzy yang diperoleh dari komposisi aturan-aturan fuzzy.

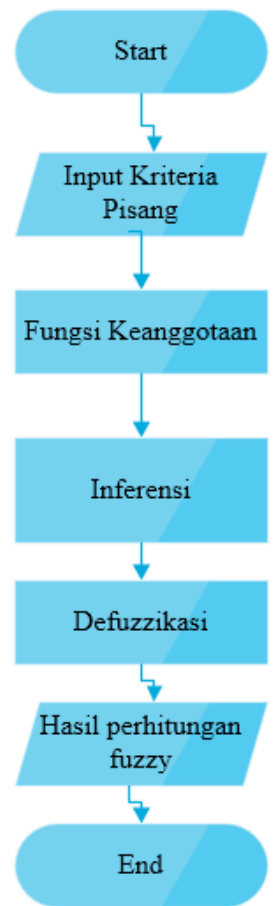

Gambar 1. Alur Algoritma Fuzzy Tsukamoto pada Sistem

Inputan dalam Fuzzy Tsukamoto ini, yaitu ukuran, kecacatan dan kesegaran. Adapun himpunan keanggotaan dari ukuran seperti Gambar 2. Himpunan keanggotaan variabel kecacatan dalam Gambar 3. Gambar 4 adalah himpunan keanggotaan kesegaran. Sedangkan output dari sistem ini adalah kelas pisang, yaitu Super, A, B, C dalam Gambar 5.

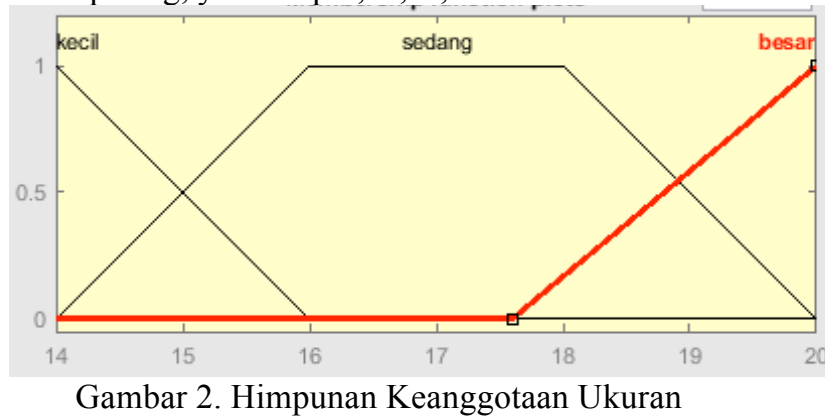

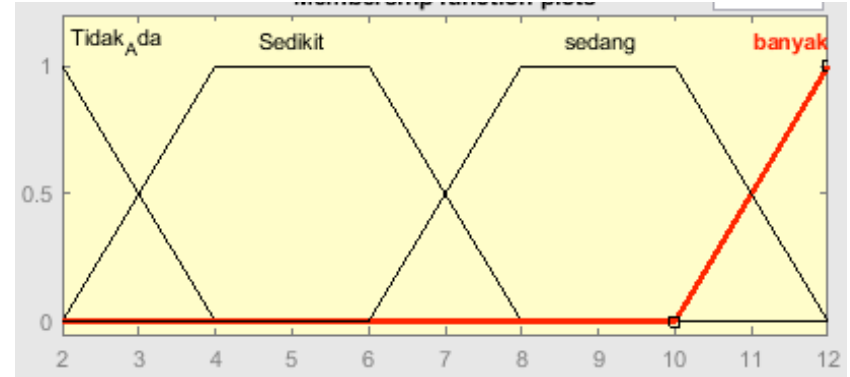

Gambar 3. Himpunan Keanggotaan Kecacatan

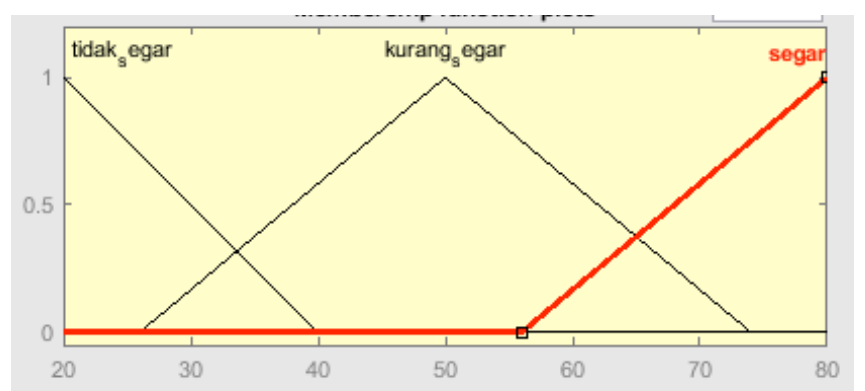

Gambar 4. Himpunan Keanggotaan Kesegaran

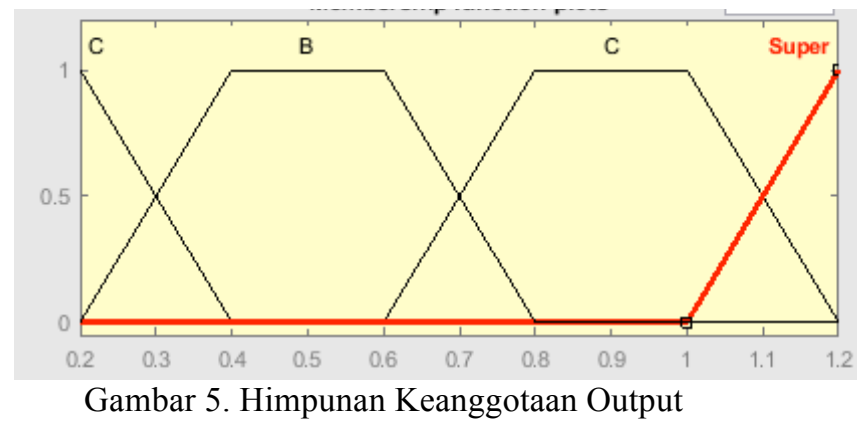

Rule dari Inferensi Fuzzy Tsukamoto pada kasus ini sebagai berikut:

[1]. IF ukuran BESAR And kecacatan TIDAK ADA And Kesegaran SEGAR THEN Kualitas SUPER

[2]. IF ukuran BESAR And kecacatan TIDAK ADA And Kesegaran KURANG SEGAR THEN Kualitas A

[3]. IF ukuran BESAR And kecacatan TIDAK ADA And Kesegaran TIDAK SEGAR THEN Kualitas B

[4]. IF ukuran BESAR And kecacatan SEDIKIT And Kesegaran SEGAR THEN Kualitas A

[5]. IF ukuran BESAR And kecacatan SEDIKIT And Kesegaran KURANG SEGAR THEN Kualitas B

[6]. IF ukuran BESAR And kecacatan SEDIKIT And Kesegaran TIDAK SEGAR THEN Kualitas C

[7]. IF ukuran BESAR And kecacatan SEDANG And Kesegaran SEGAR THEN Kualitas B

[8]. IF ukuran BESAR And kecacatan SEDANG And Kesegaran KURANG SEGAR THEN Kualitas C 
[9]. IF ukuran BESAR And kecacatan SEDANG And Kesegaran TIDAK SEGAR THEN Kualitas C

[10]. IF ukuran BESAR And kecacatan BANYAK And Kesegaran SEGAR THEN Kualitas C

[11]. IF ukuran BESAR And kecacatan BANYAK And Kesegaran KURANG SEGAR THEN Kualitas C

[12]. IF ukuran BESAR And kecacatan BANYAK And Kesegaran TIDAK SEGAR THEN Kualitas C

[13]. IF ukuran SEDANG And kecacatan TIDAK ADA And Kesegaran SEGAR THEN Kualitas A

[14]. IF ukuran SEDANG And kecacatan TIDAK ADA And Kesegaran KURANG SEGAR THEN Kualitas B

[15]. IF ukuran SEDANG And kecacatan TIDAK ADA And Kesegaran TIDAK SEGAR THEN Kualitas C

[16]. IF ukuran SEDANG And kecacatan SEDIKIT And Kesegaran SEGAR THEN Kualitas B

[17]. IF ukuran SEDANG And kecacatan SEDIKIT And Kesegaran KURANG SEGAR THEN Kualitas C

[18]. IF ukuran SEDANG And kecacatan SEDIKIT And Kesegaran TIDAK SEGAR THEN Kualitas C

[19]. IF ukuran SEDANG And kecacatan SEDANG And Kesegaran SEGAR THEN Kualitas C

[20]. IF ukuran SEDANG And kecacatan SEDANG And Kesegaran KURANG SEGAR THEN Kualitas C

[21]. IF ukuran SEDANG And kecacatan SEDANG And Kesegaran TIDAK SEGAR THEN Kualitas C

[22]. IF ukuran SEDANG And kecacatan BANYAK And Kesegaran SEGAR THEN Kualitas C

[23]. IF ukuran SEDANG And kecacatan BANYAK And Kesegaran KURANG SEGAR THEN Kualitas C

[24]. IF ukuran SEDANG And kecacatan BANYAK And Kesegaran TIDAK SEGAR THEN Kualitas C

[25]. IF ukuran KECIL And kecacatan TIDAK ADA And Kesegaran SEGAR THEN Kualitas B

[26]. IF ukuran KECIL And kecacatan TIDAK ADA And Kesegaran KURANG SEGAR THEN Kualitas C

[27]. IF ukuran KECIL And kecacatan TIDAK ADA And Kesegaran TIDAK SEGAR THEN Kualitas C

[28]. IF ukuran KECIL And kecacatan SEDIKIT And Kesegaran SEGAR THEN Kualitas C
[29]. IF ukuran KECIL And kecacatan SEDIKIT And Kesegaran KURANG SEGAR THEN Kualitas C

[30]. IF ukuran KECIL And kecacatan SEDIKIT And Kesegaran TIDAK SEGAR THEN Kualitas C

[31]. IF ukuran KECIL And kecacatan SEDANG And Kesegaran SEGAR THEN Kualitas C

[32]. IF ukuran KECIL And kecacatan SEDANG And Kesegaran KURANG SEGAR THEN Kualitas C

[33]. IF ukuran KECIL And kecacatan SEDANG And Kesegaran TIDAK SEGAR THEN Kualitas C

[34]. IF ukuran KECIL And kecacatan BANYAK And Kesegaran SEGAR THEN Kualitas C

[35]. IF ukuran KECIL And kecacatan BANYAK And Kesegaran KURANG SEGAR THEN Kualitas C

[36]. IF ukuran KECIL And kecacatan BANYAK And Kesegaran TIDAK SEGAR THEN Kualitas C

\section{Hasil dan Pembahasan}

Implementasi dari penentuan kualitas buah pisang menggunakan metode Fuzzy Tsukamoto ini terdiri dari beberapa form-form. Form-form ini akan tampil secara berurutan sesuai dengan desain program yang telah dirancang. Form Penentuan, pada Gambar 6 ini admin akan menginputkan kriteria yang akan ditentukan. Berdasarkan inputan tersebut akan dilakukan perhitungan menggunakan metode fuzzy Tsukamoto.

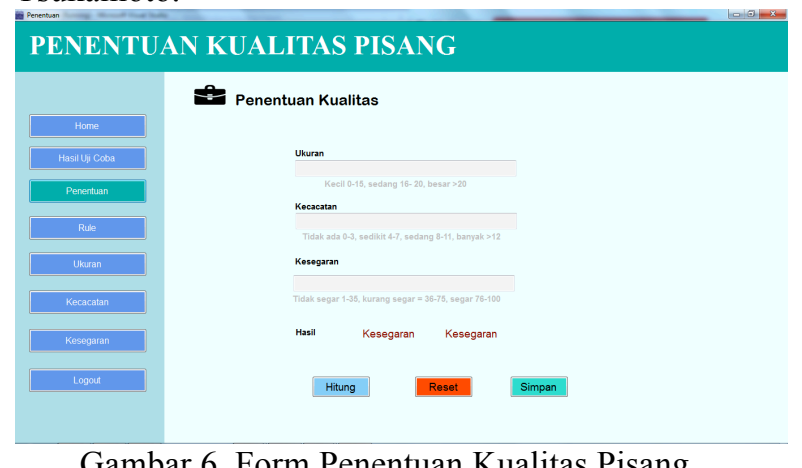

Gambar 6. Form Penentuan Kualitas Pisang

Di mana Form Fuzzy Tsukamoto adalah form hasil perhitungan penilaian kriteria pisang dengan menggunakan metode Fuzzy Tsukamoto. Dalam form Gambar 7 terdapat hasil penilaian untuk hasil akhir, yaitu kelas super, A, B, atau C. 


\section{PENENTUAN KUALITAS PISANG}

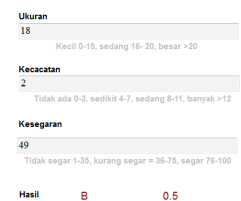

Hast $\quad$ B $\quad 0.5$

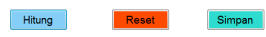

Gambar 7. Hasil Output Perhitungan Fuzzy Tsukamoto

\section{Kesimpulan dan Saran}

Dari hasil penelitian, perancangan, dan implementasi yang telah dilakukan ada kesimpulan yang dapat dikemukakan sebagai berikut: Program dengan metode fuzzy Tsukamoto dapat mempermudah dalam penentuan kualitas pisang dengan memperkecil tingkat kesalahan dalam perhitungan. Di mana hasil akurasinya $78 \%$. Cara menentukan kualitas pisang dengan metode fuzzy Tsukamoto adalah dengan menginputkan kriteria dan akan dilakukan perhitungan oleh sistem. Di mana kriteria inputannya, adalah: ukuran, Kecacatan dan Kesegaran. Output dari sistem Kelas pisang Super, A, B, dan C. Cara membuat sebuah aplikasi sistem pendukung keputusan menentukan kualitas pisang dengan menggunakan aplikasi Visual Studio 2010.

\section{Daftar Pustaka}

[1] Nadia Roosmalita Sari,Wayan Firdaus Mahmudy, "FUZZY INFERENCE SYSTEM TSUKAMOTO UNTUK MENENTUKAN KELAYAKAN CALON PEGAWAI," in Seminar Nasional Sistem Informasi Indonesia (SESINDO), Surabaya, 2015.

[2] Muqodimah Nur Lestari, Pio Arfianova Fitrizky Islami, Kirya Matreeke Moses, Aji Prasetya Wibawa, "Implementasi Metode Fuzzy Tsukamoto untuk Menentukan Hasil Tes Kesehatan pada Penerimaan Peserta Didik Baru di Sekolah Menengah Kejuruan," Register, pp. 713, 2018.

[3] Evi Nur Azizah, Imam Cholissodin, "Optimasi Fungsi Keanggotaan Fuzzy Tsukamoto Menggunakan Algoritma Genetika untuk Penentuan Harga Jual Rumah," JEEST, pp. 7982, 2015.

[4] Kemal Farouq, Miftahus Sholihin, "PENERAPAN FUZZY TSUKAMOTO DALAM PENGANGKATAN JABATAN PEGAWAI DI BKD LAMONGAN," Jurnal Teknika, pp. 1-5, 2015.

[5] SHINTIANA PUTRI, RIZKY APRILIA, "SISTEM PAKAR DIAGNOSA PENYAKIT PADA TANAMAN KAKAO MENGGUNAKAN METODE FUZZY
TSUKAMOTO," Thesis Universitas Muhammadiyah Ponorogo, Ponorogo, 2017.

[6] Miftahus Sholihin, Nurul Fuad, Nurul Khamiliyah, "Sistem Pendukung Keputusan Penentuan Warga Penerima Jamkesmas Dengan Metode Fuzzy Tsukamoto," Jurnal Teknika, pp. 1-6, 2013.

[7] Tri Murti, Leon Andretti Abdillah, Muhammad Sobri, "SISTEM PENUNJANG KEPUTUSAN KELAYAKAN PEMBERIAN PINJAMAN DENGAN METODE FUZZY TSUKAMOTO," in Seminar Nasional Inovasi dan Tren (SNIT), 2015.

[8] Popy Meilina, Nurvelly Rosanti, Nuraeni Astryani, "Sitem Pendukung Keputusan Penentuan Jumlah Produksi Barang Dengan Menggunakan Metode Fuzzy Tsukamoto," in Seminar Nasional Sains dan Teknologi, Jakarta, 2017.

[9] A. Widyansyah, "Penerapan logika fuzzy Tsukamoto pada simulasi pertumbuhan tanaman wortel (Daucus carota 1.) terhadap pengaruh pemberian komposisi pupuk urea dan pupuk kompos berbasis Xl system," Thesis Universitas Islam Negeri Maulana Malik Ibrahim, Malang, 2013. 